\title{
EDITORIAL
}

\section{The cellular pathogenesis of paroxysmal nocturnal haemoglobinuria}

\author{
A Karadimitris ${ }^{1}$ and L Luzzatto ${ }^{1,2}$ \\ ${ }^{1}$ Department of Human Genetics, Memorial Sloan-Kettering Cancer Center, New York, NY, USA; and ${ }^{2}$ National Institute for Cancer \\ Research, Genova, Italy
}

\begin{abstract}
Paroxysmal nocturnal haemoglobinuria (PNH) is a unique disorder characterised by the triad of intravascular haemolysis, thrombosis and bone marrow failure. In the early seventies it was shown that PNH is a clonal disease; and in the nineties the molecular basis of the PNH abnormality was elucidated. However, what makes a PNH clone expand is still not known. Here, we suggest that this is due to somatic cell selection, resulting from the presence in the patient of autoreactive $T$ cells that target glycosylphosphatidylinositol (GPI) in the context of an MHC-like molecule on the surface of haemopoietic stem cells. PNH cells would escape damage precisely because they have lost most or all of their ability to produce GPI. Leukemia (2001) 15, 1148-1152.
\end{abstract}

Keywords: paroxysmal nocturnal haemoglobinuria (PNH); stem cells; clonal selection; autoreactive T cells; glycosylphosphatidylinositol (GPI); CD1d

\section{Introduction}

If we look back at our efforts to understand the nature of a disease condition, there are few examples with such a variegated history as paroxysmal nocturnal haemoglobinuria (PNH). In fact, whenever a new advance in $\mathrm{PNH}$ has answered a specific question, it has posed at the same time a new question. For instance, the early finding of haemoglobinuria clearly indicated intravascular haemolysis, ${ }^{1}$ but the cause was puzzling because a high-titre autoantibody was not found. Next it was shown that haemolysis was due to abnormal susceptibility to complement, ${ }^{2,3}$ but one wondered why this abnormality was limited to only a subset of all red cells. This led to a successful test of the notion that $\mathrm{PNH}$ was a clonal disorder due to a somatic mutation: ${ }^{4,5}$ but very soon this seemed to clash with the finding that not just one, but so many different surface proteins were deficient in $\mathrm{PNH}$ cells. This paradox was solved by the finding that all these proteins had a common non-protein moiety, a glycolipid which has since become known as the glucosylphosphatidylinositol (GPI) anchor, because it tethers each one of these proteins to the cell's surface by virtue of the fact that its fatty acid residues are embedded in the membrane's lipid bilayer ${ }^{6}$ (see Figure 1). Thus, deficiency of one of the enzymes required for the biosynthesis of GPI became a good candidate for explaining the $\mathrm{PNH}$ phenotype, but it was puzzling how a single mutation (ie on one allele only), could cause complete deficiency of an enzyme. This difficulty was solved when the biosynthetic gene PIG-A was cloned and mapped to the $\mathrm{X}$ chromosome, thus neatly explaining how one hit could cause complete loss of function of the gene product. ${ }^{7}$ Today, we can define $\mathrm{PNH}$ as an acquired clonal disorder of the haemopo-

Correspondence: L Luzzatto, Instituto Scientifico Tumori, Largo Rosanna Benzi 10,16132 Genova, Italy; Fax: +39 010355573

Received 22 March 2001; accepted 22 April 2001

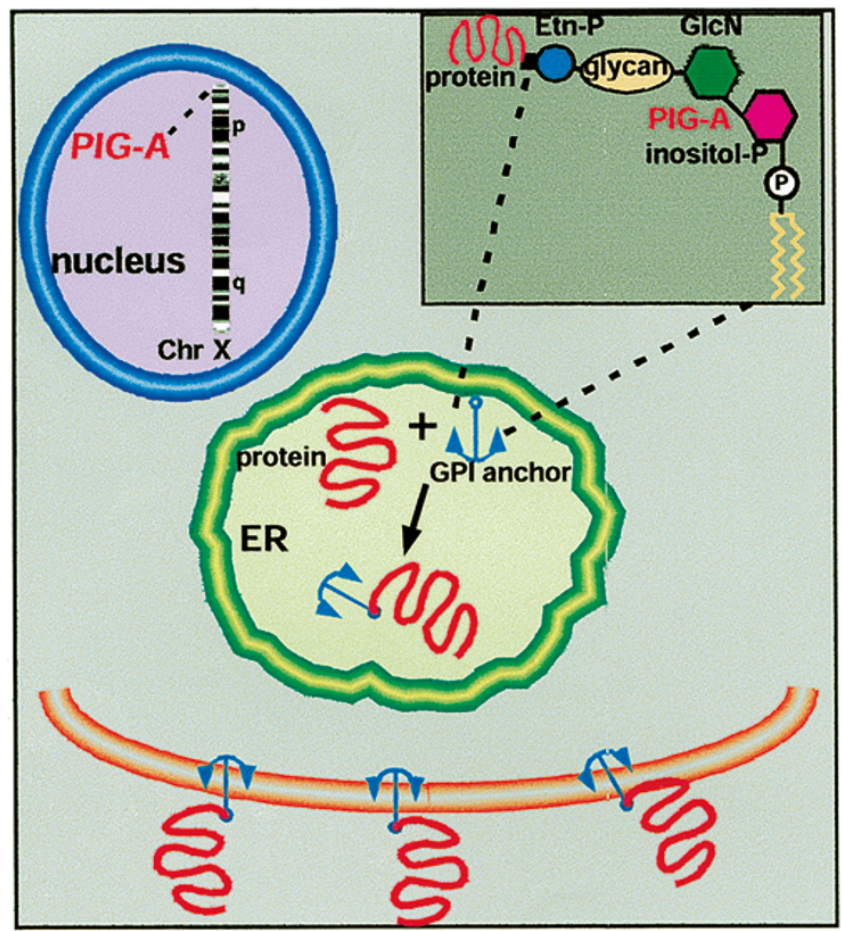

Figure 1 PIG-A, GPI anchors, GPI-anchored proteins and PNH. PIG-A is a protein encoded by the X-linked gene PIG-A. PIG-A is a member of a multi-subunit enzymatic complex which catalyzes, in the endoplasmic reticulum (ER) the first step in the biosynthesis of GPI: the addition of acetylglucosamine (GlcN) to phosphatidylinositol (inositol-P; inset). The synthesis of the GPI anchor is completed by the serial addition of a glycan moiety consisting of three mannose molecules and a molecule of phosphoethanolamine (Etn-P), to which, through a transpeptidation reaction, proteins with the appropriate carboxy-terminal amino acid motif are attached covalently. The GPIprotein complex subsequently travels to the cell surface, where the protein becomes 'anchored' to the lipid bilayer through GPI. In PNH, PIG-A has suffered a somatic mutation in one or few HSCs. As a result, very little GPI is synthesised, or none at all, with consequent severe deficiency of GPI-anchored proteins on the surface of the mutated HSCs and their progeny.

ietic stem cell (HSC). Somatic mutations in the X-linked PIGA gene of one or more HSCs result in the deficiency of GPIanchored proteins from the surface of blood cells. The mutated (PNH) HSC(s) are able to expand to such an extent that in a patient with $\mathrm{PNH}$ the $\mathrm{PNH}$ blood cells may comprise up to $>90 \%$ of the total haemopoiesis. However, we still do not know what determines (1) the size of the PNH clone, (2) the severity of the patient's pancytopenia and (3) the increased propensity to venous thrombosis: ie the three most important features of this condition in terms of clinical course and clini- 
cal outcome. ${ }^{8}$ Here, we advance a specific hypothesis that may help to answer these questions.

The vast expansion of a $\mathrm{PNH}$ clone that is seen in a patient with $\mathrm{PNH}$ cannot take place without a growth advantage. We have previously suggested that this growth advantage, rather than being absolute (as it is in leukaemia), might be relative or conditional, ie dependent on a particular bone marrow environment. ${ }^{9}$ Specifically, an injury to the normal $\left(\mathrm{GPI}^{+}\right) \mathrm{HSC}$ might spare $\mathrm{PNH}\left(\mathrm{GPI}^{-}\right) \mathrm{HSC}$. While one might certainly conceive of physical, chemical or biological agents being able to discriminate between $\mathrm{GPI}^{+}$and $\mathrm{GPI}^{-} \mathrm{HSC}$, an obvious possibility is that the damaging agent is part of an auto-immune process (see Figure 2) especially, since this is a widely accepted pathogenetic mechanism in the closely related condition, idiopathic aplastic anaemia (IAA). ${ }^{10}$ Here, we explore this model, leading on to the notion that the target of this autoimmune process could be the GPI molecule itself on HSCs.

\section{PIG-A mutations are necessary but not sufficient to cause PNH disease}

First, we summarize the current evidence that, once a PIG- $A$ mutation has taken place, there must be a mechanism for positive selection of the mutant cells, or negative selection against the non-mutated cells (dual pathogenesis of $\mathrm{PNH}$ ). There are essentially four lines of evidence. (1) PIG-A mutations are found regularly in normal people. ${ }^{11}$ (2) Non-mutated hematopoietic cells are decreased in absolute terms in patients with $\mathrm{PNH}$ (as in IAA). ${ }^{12}$ (3) Patients with PNH not infrequently have more than one mutant clone; and sometimes a different $\mathrm{PNH}$ clone can be shown to be dominant in the same patient at different points in time. ${ }^{13}$ (4) In mice with targeted inactivation of the pig-a gene the $\mathrm{PNH}$ cell population does not increase in time, and often tends to disappear. ${ }^{14-16}$ This last finding does not support positive selection for mutant cells; by implication, it favours instead the notion that negative selection against non-mutant cells dominates the picture in human $\mathrm{PNH}$ patients.
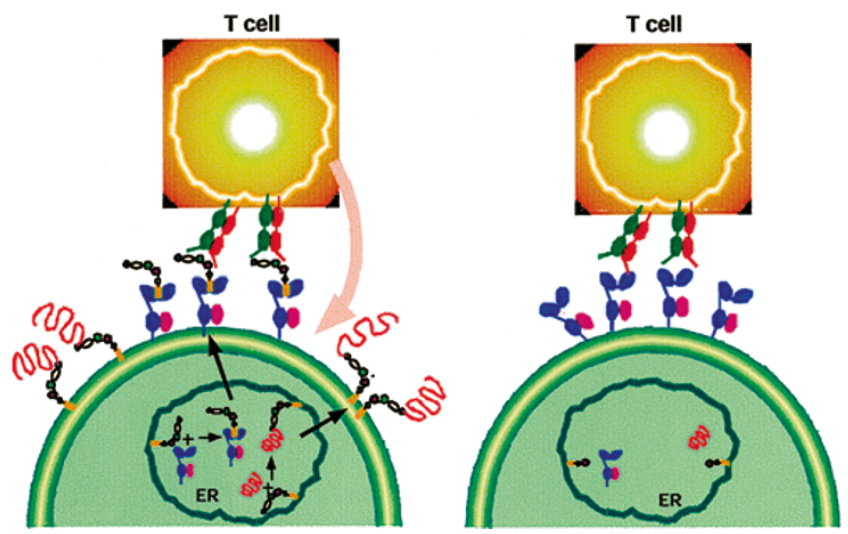

Figure 2 GPI-specific, CD1d-restricted T cells in the pathogenesis of PNH. In this hypothetical model, GPI-specific, CD1d-restricted T cells target and deplete $\mathrm{GPI}^{+}$(ie non-mutated) HSCs (left). However, $\mathrm{GPI}^{-}$HSCS, because they fail to synthesise GPI, escape the T cell attack (right), expand and contribute to haemopoiesis to various degrees.
What is the target and what is the mechanism of negative selection?

We will make the specific assumption that an autoreactive population of cytotoxic T cells inhibits the growth or causes the demise of non-mutated HSC: ie we postulate that these cells have a differential effect on $\mathrm{GPI}^{+}$and $\mathrm{GPI}^{-} \mathrm{HSC}$ (escape model). ${ }^{9}$ An increased frequency of clonal T cell expansions in patients with $\mathrm{PNH}$ is in line with this concept. ${ }^{17}$ In addition, we have recently observed two patients with an association of T-LGL and $\mathrm{PNH} .{ }^{18}$ According to this model, we consider four possible alternative targets and cognate mechanisms of selection.

The deficiency of GPI-anchored molecules from the surface of $\mathrm{PNH}$ cells helps in itself to protect them from $T$ cell-mediated attack

Indeed, it is conceivable that a GPI-linked protein is essential for effective recognition or killing by a cytotoxic T cell. However, we and others have shown in internally controlled experiments that there is no significant difference in the ability of $\mathrm{T}$ cells or NK cells to kill $\mathrm{PNH}$ haemopoietic cells $v s$ normal, isogenic haemopoietic cells. ${ }^{19}$

The target of autoaggressive T cells is an epitope belonging to the PIG-A protein itself

Because PIG-A is an intracellular protein it can become itself antigenic only if critical peptide(s) arising through endogenous processing pathways are then displayed to pathogenic cytotoxic T cells in the groove of an HLA class I molecule. ${ }^{20}$ Thus, non-PNH HSCs would process and present the putative PIGA-derived peptide and become targets of T cells; in contrast, $\mathrm{PNH}$ HSCs would escape the T cell attack because, by failing to produce the PIG-A protein as a result of a PIG-A mutation they would not present the critical peptide. A strong argument against this possibility is the fact that PIG-A is ubiquitously expressed: ${ }^{7}$ therefore, the immune process would be expected to damage cells in a variety of tissues. Instead, $\mathrm{PNH}$ is strictly a disease of haemopoiesis. In addition, there are many missense mutations in $P I G-A$ in $P N H,{ }^{21}$ and at least some of them would still produce the putative critical peptide(s). Therefore, it is unlikely that PIG-A is the target we are looking for.

\section{The target of autoaggressive T cells is an epitope derived from a GPI-anchored protein}

Although proteins destined to be GPI-linked fail to land on the surface of $\mathrm{PNH}$ cells because they do not find the anchor, they are as efficiently transcribed and translated in $\mathrm{PNH}$ cells as in non-PNH cells. This would result, in PNH cells, in the accumulation of unprocessed proteins which, in association with chaperones residing in the endoplasmic reticulum, are transferred to the cytoplasm where they are degraded. ${ }^{22}$ Thus, although it has been suggested that $\mathrm{PNH}$ cells may present a critical epitope less efficiently than $\mathrm{GPI}^{+}$cells, ${ }^{23,24}$ there is no experimental evidence to support this notion. Therefore, peptides from GPI-linked proteins do not seem at the moment good candidate targets either. 


\section{GPI itself is the target of autoaggressive $T$ cells}

It is now well established that, just as HLA molecules present peptide antigens, the $\beta 2$-microglobulin-associated CD1 molecules (CD1a, CD1b, CD1c, CD1d), expressed on professional antigen presenting cells (APC; for example, dendritic cells), present lipids or glycolipids to T cells. ${ }^{25}$ CD1a, b and c-restricted, lipid-specific immune responses have been implicated in the control of intracellular pathogens such as Myсоbacterium tuberculosis and Mycobacterium leprae. ${ }^{25}$ Similarly, CD1d-restricted, glycolipid-specific $\mathrm{T}$ cell responses may be involved in the pathogenesis of autoimmune disease, ${ }^{26}$ as well as in the immunity against intracellular pathogens $^{27}$ and possibly against certain types of cancer. ${ }^{28} \mathrm{~A}$ finding potentially very pertinent to $\mathrm{PNH}$ is the that murine CD1d contains GPI in its presentation groove, ${ }^{29}$ and parasite GPI may be the target of protective $\mathrm{T}$ cell immunity in murine malaria. ${ }^{30}$

On the basis of these data, we favour the hypothesis that CD1d-restricted, GPI-specific T cells are central to the pathogenesis of $\mathrm{PNH}$. Specifically, we envisage that some of the expanded $\mathrm{T}$ cell clones - which we have demonstrated in PNH patients - recognize GPI presented in the context of CD1d by HSCs, and thus attack these cells. By contrast, the PNH HSC, since they synthesise very little GPI, or none at all, will be able to escape the T cell attack. This model implies that pluripotential HSCs must express CD1d at some stage. This has not yet been tested.

This hypothesis might also help to explain the pathogenesis of venous thrombosis, one of the most dreaded complications of $\mathrm{PNH}$, since it affects up to $40 \%$ of patients and it is a leading cause of mortality. ${ }^{8}$ For reasons which have been obscure hitherto, in $\mathrm{PNH}$ venous thrombosis has a special predilection for intra-abdominal and cerebral veins. ${ }^{8}$ Interestingly, CD1d, among other tissues, is also expressed in the muscle layer of abdominal blood vessels. ${ }^{31}$

\section{Testing hypothesis 4}

The crucial proof for this model must consist in demonstrating the presence in $\mathrm{PNH}$ patients of autoreactive $\mathrm{T}$ cells that recognize the GPI molecule. The identification of antigen-specific $T$ cells in clinical samples has relied traditionally on stimulating their growth by having the appropriate antigenic peptide presented by appropriate APC. The functional readout consists in cytotoxicity, proliferation assays or cytokine secretion assays. A recent powerful advance has been the introduction of HLA class I-peptide tetrameric complexes ${ }^{32,33}$ (Figure 3a). By using tetramer technology it is possible to identify, quantitate and sort specific $\mathrm{CD}^{+} \mathrm{T}$ cells with a sensitivity as high as $0.01 \% .^{34,35}$

We propose therefore that using CD $1 \mathrm{~d} / \beta 2 \mathrm{~m} / \mathrm{GPI}$ tetramers would be the best way to experimentally test our hypothesis. In order to provide proof of principle that this approach is feasible, we have already constructed CD1d tetramers, with the glycolipid $\alpha$-galactosylceramide ( $\alpha$-GalCer) in the presentation groove. The sensitivity of this technique has been validated $^{36}$ (see Figure $3 \mathrm{~b}$ ). The next step would be to construct CD1d tetramers with GPI instead of $\alpha$-GalCer, and use them to stain lymphocytes from $\mathrm{PNH}$ patients and control individuals. CD1d/GPI tetramer ${ }^{+} \mathrm{T}$ cells can be then flow-sorted, and their specificity confirmed in proliferation, cytotoxicity or cytokine secretion assays in the presence of CD1d-expressing APC pulsed with GPI. Finally, the role of these cells in the a

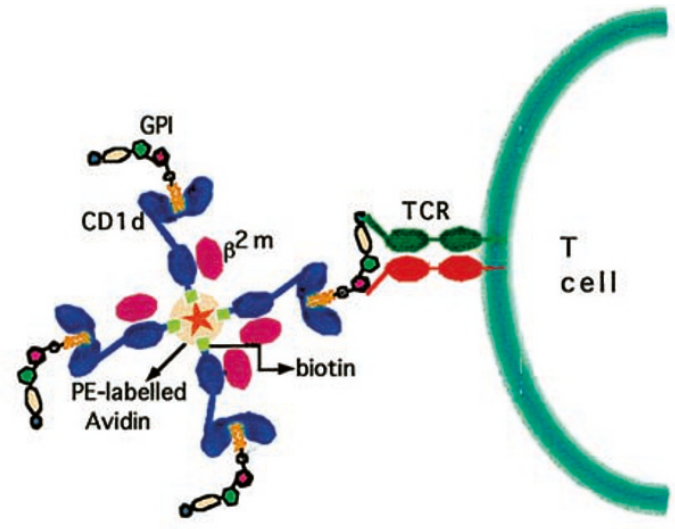

b
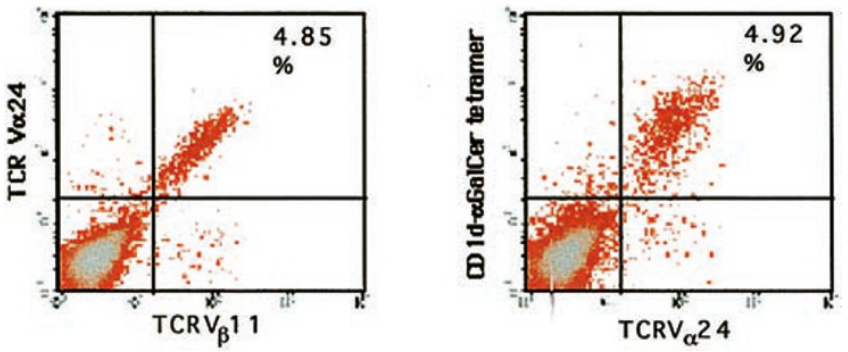

Figure 3 Testing of the hypothesis: identification of GPI-specific, CD1d-restricted T cells using tetramer technology. (a) The basic structural unit of a tetramer is a tri-partite complex (referred to as monomer) of an HLA class I heavy chain (replaced by CD1d in this case), $\beta 2$ microglobulin and a peptide (replaced by a glycolipid in this case), which must be correctly refolded in vitro. A biotinylation signal oligopeptide was engineered at the carboxy-terminus of CD1d in order to facilitate the enzymatic biotinylation of the monomeric complexes, which in turn enables us to form and purify tetramers by the addition of the tetravalent, phycoerythrin (PE)-conjugated (Extra)Avidin. The tetrameric complex binds to its cognate $\mathrm{T}$ cell receptor and thus tags the T cells of interest, which can be identified, counted and characterised in vitro as well as ex vivo in terms of their immunophenotype, with a sensitivity as low as $0.01 \%$. (b) We have constructed a CD 1 d$\alpha$-GalCer tetramer which binds to T cells specific for the glycolipid $\alpha$-GalCer. Characteristically, such T cells bear a T cell receptor made of the un-mutated $\alpha$-chain $\vee \alpha 24$ and the semi-invariant $\beta$ chain $\mathrm{V} \beta 11$. The frequency of TCR $V \alpha 24^{+} / \mathrm{N} \beta 11^{+} \mathrm{T}$ cells was increased in vitro by culturing blood lymphocytes from a normal donor in the presence of antigen presenting cells, $\alpha$-GalCer and interleukin-2. Staining with PElabelled anti-TCR $\vee \alpha 24$ and FITC-labelled anti-TCR V $\beta 11$ and analysis by flow cytometry revealed that $4.85 \%$ of the cells were TCR $\mathrm{V} \alpha 24^{+} \mathrm{N} \beta 11^{+}$(left); staining with the CD1d- $\alpha$ GalCer tetramer showed that a similar proportion of cells was CD1d- $\alpha$ GalCer tetramer ${ }^{+} / \mathrm{TCR}$ $\mathrm{V} \alpha 24^{+}$(right). For the identification of GPI-specific, CD1d-restricted T cells in PNH patients, we will use CD1d tetramers containing GPI instead of $\alpha$-GalCer.

pathogenesis of $\mathrm{PNH}$ could be proved directly by showing, in functional assays, that they are able to inhibit normal haemopoiesis but not $\mathrm{PNH}$ haemopoiesis.

\section{Conclusion}

At the time the escape model for the pathogenesis of $\mathrm{PNH}$ was first proposed, more than a decade ago, ${ }^{9}$ it was merely a concept based on the need to explain why the $\mathrm{PNH}$ clone was able to expand, and yet it did not have the features of 
leukaemia. The model has proved to have heuristic value, because we now know the molecular basis for the $\mathrm{PNH}$ abnormality, we know that $\mathrm{PNH}$ clones are present but do not expand in normal people, ${ }^{11}$ and we know that PNH cells tend to disappear rather than to expand in mouse model systems. ${ }^{14-}$ 16 Moreover, we have evidence that the conditional selective agent we had postulated may consist in T cell clones, because we have demonstrated such clones in a substantial proportion of $\mathrm{PNH}$ patients. ${ }^{17} \mathrm{CD} 1 \mathrm{~d}$ tetramer technology may help to prove that these clones have the properties that we have hypothetically ascribed to them. Most important, if the hypothesis is correct, this may open up new possibilities for the treatment of $\mathrm{PNH}$, and possibly of other conditions in which similar pathogenetic mechanisms are in operation.

\section{Acknowledgements}

We warmly thank all the present and past members of the Human Molecular Genetics Laboratory in the Department of Human Genetics at MSKCC, New York; the ideas discussed in this paper have developed through the hard work of everyone in the PNH group. In particular, we thank David Araten, Monica Bessler, Khedoudja Nafa, Rosario Notaro and Vittorio Rosti. We also thank immensely Vincenzo Cerundolo and Stephan Gadola of Oxford, UK, for their role in the CD1 tetramer work. Finally, we thank Irene AG Roberts, London, for her enthusiastic support of our endeavours; and Bruno Rotoli of Napoli, Italy with whom for two decades we have shared efforts to shed light on the cellular pathogenesis of $\mathrm{PNH}$. The authors' research work has been supported by a grant from the National Institutes of Health (No. RO1 HL56778).

\section{References}

1 Strubing P. Paroxysmale hamoglobinurie. Dtsch Med Wochenschr $1882 ; 8: 1-8$.

2 Dacie JV, Israels MCG, Wilkinson JF. Paroxysmal nocturnal haemoglobinuria of the Marchiafava type. Lancet 1939; i: 479-482.

3 Ham TH, Dingle JH. Studies on destruction of red blood cells. II. Chronic hemolytic anemia with paroxysmal nocturnal hemoglobinuria: certain immunological aspects of the hemolytic mechanism with special reference to serum complement. J Clin Invest 1938; 18: $657-672$

4 Lewis SM, Dacie JV. The aplastic anaemia-paroxysmal nocturnal haemoglobinuria syndrome. Br J Haematol 1967; 13: 236-251.

5 Oni SB, Osunkoya BO, Luzzatto L. Paroxysmal nocturnal hemoglobinuria: evidence for monoclonal origin of abnormal red cells. Blood 1970; 36: 145-152.

6 Englund PT. The structure and biosynthesis of glycosyl phosphatidylinositol protein anchors. Annu Rev Biochem 1993; 62: 121-138.

7 Takeda J, Miyata T, Kawagoe K, lida Y, Endo Y, Fujita T, Takahashi M, Kitani T, Kinoshita T. Deficiency of the GPI anchor caused by a somatic mutation of the PIG-A gene in paroxysmal nocturnal hemoglobinuria. Cell 1993; 73: 703-711.

8 Hillmen P, Lewis SM, Bessler M, Luzzatto L, Dacie JV. Natural history of paroxysmal nocturnal hemoglobinuria. N Engl J Med 1995; 333: 1253-1258.

9 Rotoli B, Luzzatto L. Paroxysmal nocturnal haemoglobinuria. Baillières Clin Haematol 1989; 2: 113-138.

10 Young NS, Maciejewski J. The pathophysiology of acquired aplastic anemia. N Engl J Med 1997; 336: 1365-1372.

11 Araten DJ, Nafa K, Pakdeesuwan K, Luzzatto L. Clonal populations of hematopoietic cells with paroxysmal nocturnal hemoglobinuria genotype and phenotype are present in normal individuals. Proc Natl Acad Sci USA 1999; 96: 5209-5214.

12 Maciejewski JP, Sloand EM, Sato T, Anderson S, Young NS. Impaired hematopoiesis in paroxysmal nocturnal hemoglobinuria/aplastic anemia is not associated with a selective pro- liferative defect in the glycosylphosphatidylinositol-anchored protein-deficient clone. Blood 1997; 89: 1173-1181.

13 Luzzatto L, Nafa K. Genetics of PNH. In: Young NS, Moss J (eds). PNH and GPI-linked Proteins. Academic Press: San Diego, 2000, pp 21-48.

14 Tremml G, Dominguez C, Rosti V, Zhang Z, Pandolfi PP, Keller $P$, Bessler M. Increased sensitivity to complement and a decreased red blood cell life span in mice mosaic for a nonfunctional Piga gene (see comments). Blood 1999; 94: 2945-2954.

15 Rosti V, Tremml G, Soares V, Pandolfi PP, Luzzatto L, Bessler M. Murine embryonic stem cells without pig-a gene activity are competent for hematopoiesis with the $\mathrm{PNH}$ phenotype but not for clonal expansion (see comments). J Clin Invest 1997; 100: 1028-1036.

16 Murakami Y, Kinoshita T, Maeda Y, Nakano T, Kosaka H, Takeda J. Different roles of glycosylphosphatidylinositol in various hematopoietic cells as revealed by a mouse model of paroxysmal nocturnal hemoglobinuria. Blood 1999; 94: 2963-2970.

17 Karadimitris A, Manavalan JS, Thaler HT, Notaro R, Araten DJ, Nafa K, Roberts IA, Weksler ME, Luzzatto L. Abnormal T-cell repertoire is consistent with immune process underlying the pathogenesis of paroxysmal nocturnal hemoglobinuria. Blood 2000; 96: 2613-2620.

18 Karadimitris A, Li K, Notaro R, Araten D, Nafa K, Thertulien R, Ladanyi M, Stevens A, Roberts I, Luzzatto L. A novel association of T-LGL leukemia and PNH supports the central role $f$ a T-cellmediated immune response in the pathogenesis of $\mathrm{PNH}$. Blood 2000; 96: 995a.

19 Karadimitris A, Notaro R, Koehne G, Roberts IA, Luzzatto L. PNH cells are as sensitive to T-cell-mediated lysis as their normal counterparts: implications for the pathogenesis of paroxysmal nocturnal haemoglobinuria. Br J Haematol 2000; 111: 1158-1163.

20 Pamer E, Cresswell P. Mechanisms of MHC class I-restricted antigen processing. Annu Rev Immunol 1998; 16: 323-358.

21 Nafa K, Mason PJ, Hillmen P, Luzzatto L, Bessler M. Mutations in the PIG-A gene causing paroxysmal nocturnal hemoglobinuria are mainly of the frameshift type. Blood 1995; 86: 4650-4655.

22 Wang Y, Chen D, Androlewicz MJ. The role of endoplasmic reticulum-associated protein degradation in MHC class I antigen processing. Immunol Rev 1999; 172: 67-72.

23 Dunn DE, Liu JM, Young NS. Bone marrow failure in $\mathrm{PNH}$. In: Young NS, Moss J (eds). PNH and GPI-linked Proteins. Academic Press: San Diego, 2000, pp 115-131.

24 Young NS, Maciejewski JP. Genetic and environmental effects in paroxysmal nocturnal hemoglobinuria: this little PIG-A goes 'Why? Why? Why?'. I Clin Invest 2000; 106: 637-641.

25 Porcelli SA, Modlin RL. The CD1 system: antigen-presenting molecules for T cell recognition of lipids and glycolipids. Annu Rev Immunol 1999; 17: 297-329.

26 Wilson SB, Kent SC, Patton KT, Orban T, Jackson RA, Exley M, Porcelli S, Schatz DA, Atkinson MA, Balk SP, Strominger JL, Hafler DA. Extreme Th1 bias of invariant Valpha24JalphaQ T cells in type 1 diabetes. Nature 1998; 391: 177-181.

27 Kumar H, Belperron A, Barthold SW, Bockenstedt LK. Cutting edge: CD1d deficiency impairs murine host defense against the spirochete, borrelia burgdorferi. J Immunol 2000; 165: 47974801.

28 Toura I, Kawano T, Akutsu Y, Nakayama T, Ochiai T, Taniguchi $M$. Cutting edge: inhibition of experimental tumor metastasis by dendritic cells pulsed with alpha-galactosylceramide. J Immunol 1999; 163: 2387-2391.

29 Joyce S, Woods AS, Yewdell JW, Bennink JR, De Silva AD, Boesteanu A, Balk SP, Cotter RJ, Brutkiewicz RR. Natural ligand of mouse CD1d1: cellular glycosylphosphatidylinositol. Science 1998; 279: $1541-1544$.

30 Schofield L, McConville MJ, Hansen D, Campbell AS, Fraser-Reid B, Grusby MJ, Tachado SD. CD1d-restricted immunoglobulin G formation to GPI-anchored antigens mediated by NKT cells. Science 1999; 283: 225-229.

31 Canchis PW, Bhan AK, Landau SB, Yang L, Balk SP, Blumberg RS. Tissue distribution of the non-polymorphic major histocompatibility complex class I-like molecule, CD1d. Immunology 1993; 80: $561-565$.

32 Ogg GS, McMichael AJ. HLA-peptide tetrameric complexes. Curr Opin Immunol 1998; 10: 393-396. 
33 Altman JD, Moss PAH, Goulder PJR, Barouch DH, McHeyzer-Williams MG, Bell JI, McMichael AJ, Davis MM. Phenotypic analysis of antigen-specific T lymphocytes. Science 1996; 274: 94-96.

34 Dunbar PR, Ogg GS, Chen J, Rust N, van der Bruggen P, Cerundolo $\mathrm{V}$. Direct isolation, phenotyping and cloning of low-frequency antigen-specific cytotoxic $\mathrm{T}$ lymphocytes from peripheral blood. Curr Biol 1998; 8: 413-416.

35 He XS, Rehermann B, Lopez-Labrador FX, Boisvert J, Cheung R, Mumm J, Wedemeyer $H$, Berenguer M, Wright TL, Davis MM,
Greenberg HB. Quantitative analysis of hepatitis C virus-specific CD8(+) T cells in peripheral blood and liver using peptide-MHC tetramers. Proc Natl Acad Sci USA 1999; 96: 5692-5697.

36 Karadimitris A, Gadola S, Altamirano M, Brown D, Woolfson A, Klenerman P, Chen JL, Koezuka Y, Roberts IA, Price DA, Dusheiko G, Milstein C, Fersht A, Luzzatto L, Cerundolo V. From the cover: human CD1d-glycolipid tetramers generated by in vitro oxidative refolding chromatography. Proc Natl Acad Sci USA 2001; 98: 3294-3298. 